\title{
Synthesis and electrochemical properties of nickel oxide coated $\mathrm{ZnMn}_{2} \mathrm{O}_{4}$ nanocomposites
}

\author{
Yongjie LI ${ }^{1,2}$, Zhiqiang $\mathrm{WEI}^{1,2, \dagger}$, Meijie DING ${ }^{2}$, Long $\mathrm{MA}^{2}$, Xueliang $\mathrm{ZHU}^{2}$ and Jiahao LIANG ${ }^{2}$ \\ ${ }^{1}$ State Key Laboratory of Advanced Processing and Recycling of Non-ferrous Metals, Lanzhou University of Technology, \\ Lanzhou 730050, China \\ ${ }^{2}$ School of Science, Lanzhou University of Technology, Lanzhou 730050, China
}

\begin{abstract}
Nickel oxide coated $\mathrm{ZnMn}_{2} \mathrm{O}_{4}$ nanocomposites were successfully synthesized by two-step method combined hydrothermal reaction and calcination process. The microstructure, morphology and the color mapping of the as-prepared samples were characterized by means of $\mathrm{X}$-ray diffraction, high resolution electronic microscope microstructure, field emission scanning electron microscopy and energy-dispersive X-ray spectrum. The electrochemical performance of the samples were investigated by cyclic volt-ampere $(\mathrm{CV})$, constant-current charge-discharge and electrochemical impedance spectroscopy. The experimental results show that nickel oxide coated $\mathrm{ZnMn}_{2} \mathrm{O}_{4}$ nanocomposites exhibit weak $\mathrm{Ni}_{2} \mathrm{O}_{3}$ hexagonal phase besides obvious $\mathrm{ZnMn}_{2} \mathrm{O}_{4}$ spinel tetragonal structure, the morphologies are uniform polyhedron structure with obvious cladding layer. $\mathrm{CV}$ curves exhibit rectangular shape without obvious redox peaks. Nickel oxide coated $\mathrm{ZnMn}_{2} \mathrm{O}_{4}$ nanocomposites shows better specific capacitance and excellent cyclic stability, and maintains $98.8 \%$ of its initial capacitance after 1200 cycles. Nyquist plots of nickel oxide coated $\mathrm{ZnMn}_{2} \mathrm{O}_{4}$ nanocomposites proving the samples possess lower resistance and ideal electron conductivity.

(C2019 The Ceramic Society of Japan. All rights reserved.
\end{abstract}

Key-words : Nickel oxide, $\mathrm{ZnMn}_{2} \mathrm{O}_{4}$, Polyhedron structure, Electrochemical performance

[Received January 13, 2019; Accepted May 13, 2019]

\section{Introduction}

In recent decades, with the rapid growth of global population and economy, the energy crisis and environmental pollution have become increasingly serious, and the development and utilization of efficient and clean new energy sources have received increasing attention. ${ }^{1)-5)}$ Supercapacitors is a new type of energy storage devices between electrolytic capacitors and rechargeable batteries, ${ }^{6)-8)}$ which has attracted extensive attention as unique electrochemical energy storage devices due to its long cycling life, large power density, moderate energy density, fast chargedischarge speed and wide operating temperature range. ${ }^{9-14)}$ Hence, several materials have been explored as electrode materials for energy storage applications. In contrast, spinel mixed metal oxides have been extensively studied and applied as electrode materials for supercapacitors due to their higher specific capacity than carbon materials and better cyclic stability than conductive polymers. ${ }^{15)-20)}$

$\mathrm{ZnMn}_{2} \mathrm{O}_{4}$ is a typical spinel type mixed metal oxide with narrow band gap of $1.86 \mathrm{eV}$, and belonging to $\mathrm{I} 41$ / amd space group. ${ }^{21)}$ It was demonstrated that $\mathrm{ZnMn}_{2} \mathrm{O}_{4}$

\footnotetext{
$\dagger$ Corresponding author: Z. Wei; E-mail: 2667355047@qq. com
}

nanocrystals exhibit higher specific capacitance, but the cycle stability is poor, ${ }^{22), 23}$ while transition metal oxide possess better cycle stability, but the specific capacitance is lower. ${ }^{24)-26)}$ Therefore, it is very significative to combine the advantages of the two types of spinel type mixed metal oxide and transition metal oxides to make them have higher specific capacitance and better cycle stability. ${ }^{27)-29)}$ In particular, nanostrucures have great potential to achieve excellent electrochemical properties due to nanostructures can provide relatively short diffusion paths and relatively high surface area. ${ }^{30), 31)}$ Unfortunately, to the best of our knowledge, there are few reports on the electrochemical properties of nanocomposites about spinel type mixed metal oxides and transition metal oxides.

In this paper, nickel oxide coated $\mathrm{ZnMn}_{2} \mathrm{O}_{4}$ nanocomposites with spinel tetragonal structure were successfully synthesized by two-step method combined hydrothermal reaction and calcination process. The samples were evaluated by means of X-ray diffraction (XRD), field emission scanning electron microscopy (FESEM) and energydispersive X-ray spectrum, high resolution electronic microscope microstructure (HRTEM), cyclic voltammetry (CV), galvanostatic charge-discharge (GCD), cycle stability and electrochemical impedance spectra (EIS) to compare the microstructure and supercapacitor perform- 
ances of $\mathrm{ZnMn}_{2} \mathrm{O}_{4}$ and nickel oxide coated $\mathrm{ZnMn}_{2} \mathrm{O}_{4}$ nanocomposites.

\section{Experimental}

\subsection{Materials preparation}

Nickel oxide coated $\mathrm{ZnMn}_{2} \mathrm{O}_{4}$ nanocomposites were synthesized by two-step method combined hydrothermal reaction and calcination process. In a typical procedure, according to the molar ratio of the metal cations (the atomic weight ratio of $\mathrm{Ni}: \mathrm{Mn}$ in this experiment is $5 \%$ ), weighed stoichiometric amounts of $\mathrm{Zn}\left(\mathrm{NO}_{3}\right)_{2} \cdot 6 \mathrm{H}_{2} \mathrm{O}$, $\mathrm{Ni}\left(\mathrm{NO}_{3}\right)_{2} \cdot 9 \mathrm{H}_{2} \mathrm{O}$ and $\mathrm{Mn}\left(\mathrm{NO}_{3}\right)_{2} \cdot 6 \mathrm{H}_{2} \mathrm{O}$ used as precursors. $\mathrm{ZnMn}_{2} \mathrm{O}_{4}$ nanocrystals were synthesized via a facile hydrothermal method as described in literature. ${ }^{22)}$ A certain amount of nickel nitrate was weighed and dissolved in $100 \mathrm{~mL}$ anhydrous ethanol under constant magnetic stirring for $30 \mathrm{~min}$. Then slowly added $\mathrm{ZnMn}_{2} \mathrm{O}_{4}$ powders to the above solution, and the suspension solution was evenly dispersed by magnetic stirring at room temperature for $1 \mathrm{~h}$. Subsequently, the resultant solution was transferred to and sealed in a Teflon- lined stainless-steel autoclave of 100 $\mathrm{mL}$ capacity and submitted to hydrothermal treatment at $100^{\circ} \mathrm{C}$, After reaction for $12 \mathrm{~h}$, the autoclave was naturally cooled down to room temperature. Thereafter, the produced precipitate was separated centrifugally and washed several times with distilled water and absolute alcohol, respectively, and then dried at $60^{\circ} \mathrm{C}$ in a vacuum oven for $10 \mathrm{~h}$. Finally, the products were heated treatment at $700^{\circ} \mathrm{C}$ for $6 \mathrm{~h}$ in the tube furnace. Thus, nickel oxide coated $\mathrm{ZnMn}_{2} \mathrm{O}_{4}$ nanocrystals were collected and used for further studies.

\subsection{Characterization}

The crystallographic data for the products were examined by XRD with $\mathrm{Cu} \mathrm{K} \alpha$ radiation at $\lambda=0.154056 \mathrm{~nm}$. The $2 \theta$ range scanned was 20 to $80^{\circ}$ with scanning rate $0.005^{\circ} \cdot \mathrm{s}^{-1}$ and step size $0.02^{\circ}$. The morphology and the atomic percentage of the compositions along with the color mapping of the samples was investigated by HRTEM (JEOL JEM-2010), FESEM (JEOL JSM-6701F) and Energy dispersive analysis of X-ray.

The electrochemical performance of were tested on an electrochemical workstation (CS350, Wuhan CorrTest, China) in $\mathrm{Na}_{2} \mathrm{SO}_{4}$ aqueous solution with a concentration of $1 \mathrm{M}$ as the electrolyte. Three-electrode cell configuration which including working electrode, counterelectrode, and reference electrode. Platinum foil served as the counter electrode, and standard calomel electrode served as the reference electrode, respectively. The work electrode was fabricated as follows: active substance, acetylene black and polyvinylidene fluoride were mixed at weight ratio of $8: 1: 1$ using ethyl alcohol as solvent to form slurry. The slurry was uniformly coated on the surface of nickel foam. Then the meshes were dried at $80^{\circ} \mathrm{C}$ for $12 \mathrm{~h}$ and pressed under $10 \mathrm{MPa}$. The mass of the samples on the $\mathrm{Ni}$ foam electrode was $2 \mathrm{mg} \cdot \mathrm{cm}^{-2}$ as the working electrode. The electrochemical performance of the as-prepared samples was investigated by CV, GCD and EIS.

\section{Results and discussion}

Figure 1 shows the XRD patterns of bare $\mathrm{ZnMn}_{2} \mathrm{O}_{4}$ and nickel oxide coated $\mathrm{ZnMn}_{2} \mathrm{O}_{4}$ nanocomposites, as well as the standard XRD patterns of $\mathrm{ZnMn}_{2} \mathrm{O}_{4}$ tetragonal structure (PDF \#71-2499) and $\mathrm{Ni}_{2} \mathrm{O}_{3}$ hexagonal structure (PDF \#14-0481). For bare $\mathrm{ZnMn}_{2} \mathrm{O}_{4}$ sample, all the diffraction peaks can well correspond to the standard diffraction pattern of tetragonal $\mathrm{ZnMn}_{2} \mathrm{O}_{4}$ (space group: I41/amd, $a=b=0.5720 \mathrm{~nm}, c=0.9245 \mathrm{~nm})$, There is no impurity diffraction peak in the pattern, indicating a high purity of the sample. It can be found that $\mathrm{ZnMn}_{2} \mathrm{O}_{4}$ nanocrystals before and after coating nickel oxide coating did not cause structural change, and maintain the tetragonal structure. In addition, additional weak diffraction peaks from $\mathrm{Ni}_{2} \mathrm{O}_{3}$ hexagonal phase can be seen in the XRD pattern of the composite, which indicates that $\mathrm{Ni}_{2} \mathrm{O}_{3}$ nanoparticles are formed in the composite.

The SEM images of $\mathrm{ZnMn}_{2} \mathrm{O}_{4}$ and nickel oxide coated $\mathrm{ZnMn}_{2} \mathrm{O}_{4}$ nanocomposites are shown in Fig. 2. It can be seen that bare $\mathrm{ZnMn}_{2} \mathrm{O}_{4}$ exhibits irregular polyhedron shape with average size of several hundred $\mathrm{nm}$. The surface is rough and unclear with obvious agglomeration phenomenon, A large number of particles densely piled together and forming honeycomb-like morphology. Figure 2(b) presents SEM image of nickel oxide coated $\mathrm{ZnMn}_{2} \mathrm{O}_{4}$ nanocomposites, revealing that the particles present uniform polyhedron structure with clear boundaries and smooth surface, the microstructure and morphology of $\mathrm{ZnMn}_{2} \mathrm{O}_{4}$ sample after coating treatment without change, but the particle boundary become clear with a certain degree of agglomeration.

Figure 3(a) shows the dark-field FESEM image of nickel oxide coated $\mathrm{ZnMn}_{2} \mathrm{O}_{4}$ nanocomposites, Figs. 3(b)3(e) give the color mapping image of corresponding elements in the area indicated in Fig. 3(a). Morphology of nickel oxide coated $\mathrm{ZnMn}_{2} \mathrm{O}_{4}$ composites reveals regular polyhedron structure with more or less agglomeration. The element mapping images of the composite material

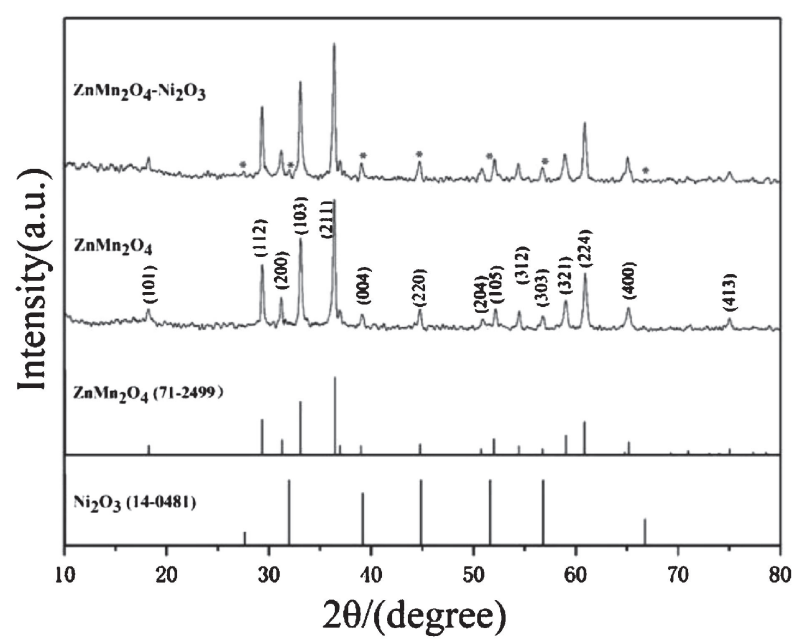

Fig. 1. XRD patterns of $\mathrm{ZnMn}_{2} \mathrm{O}_{4}$ and nickel oxide coated $\mathrm{ZnMn}_{2} \mathrm{O}_{4}$ nanocomposites. 

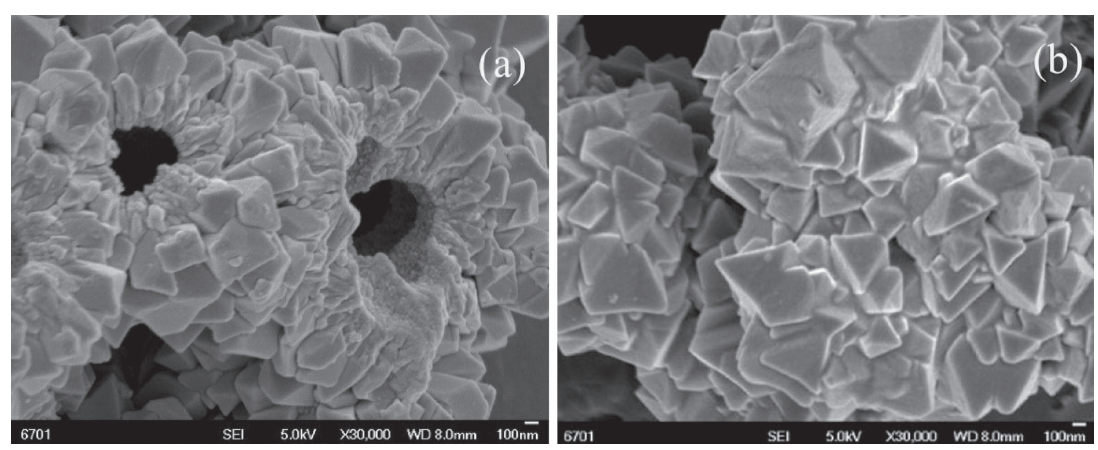

Fig. 2. SEM images of (a) $\mathrm{ZnMn}_{2} \mathrm{O}_{4}$ and (b) nickel oxide coated $\mathrm{ZnMn}_{2} \mathrm{O}_{4}$ nanocomposite.
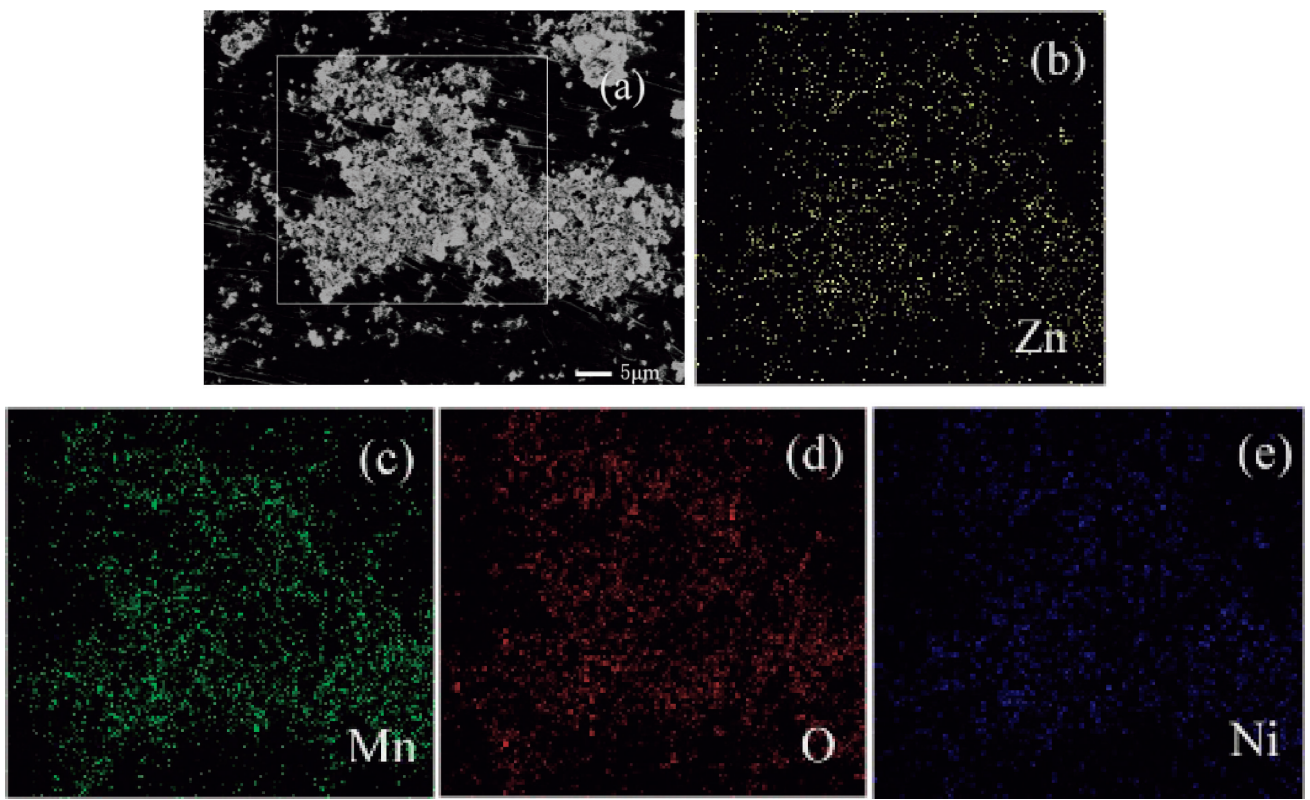

Fig. 3. (a) FESEM image and (b-e) the corresponding elemental mapping images of nickel oxide coated $\mathrm{ZnMn}_{2} \mathrm{O}_{4}$ nanocomposites.

confirms that $\mathrm{Zn}, \mathrm{Mn}, \mathrm{O}$ and Ni elements are evenly distributed, and the composite material without obvious chemical composition segregation in the composite phase according to the molar concentration of its precursor. In addition, the uniform distribution of $\mathrm{Ni}$ elements on the whole micro-cuboid further proves that nickel oxide has a uniform coating on the surface of $\mathrm{ZnMn}_{2} \mathrm{O}_{4}$.

Figure 4 shows the HRTEM observation results of nickel oxide coated $\mathrm{ZnMn}_{2} \mathrm{O}_{4}$ composites. It can be seen from Fig. 4(a) that nickel oxide coated $\mathrm{ZnMn}_{2} \mathrm{O}_{4}$ nanoparticles are closely aligned together with clear edges and smooth surface, most of the nanoparticle surface have obvious surface coating layer. Figure 4(b) displays the local high magnification HRTEM micrographs of nickel oxide coated $\mathrm{ZnMn}_{2} \mathrm{O}_{4}$ composites. it is evident that $\mathrm{Ni}_{2} \mathrm{O}_{3}$ encapsulated $\mathrm{ZnMn}_{2} \mathrm{O}_{4}$ nanoparticles with obvious cladding structure. For $\mathrm{Ni}_{2} \mathrm{O}_{3}$ and $\mathrm{ZnMn}_{2} \mathrm{O}_{4}$ nanoparticles, the perfect lattice fringes are clearly visible, which implying that the sample has good crystallization without obvious internal defects. The interlayer distance is about $0.25 \mathrm{~nm}$, which is well matched with the inter planar distance of the (211) lattice planes of $\mathrm{ZnMn}_{2} \mathrm{O}_{4}$ tetragonal structure, and exhibit a well oriented growth along the (211) direction. while the thickness of cladding layer approximately $6 \mathrm{~nm}$, and the lattice spacing of the crystalline cladding layer is about $0.28 \mathrm{~nm}$, which is well agreement with values the (002) lattice planes of $\mathrm{Ni}_{2} \mathrm{O}_{3}$ hexagonal structure. HRTEM observation results are consistent with the XRD results, which further indicating that $\mathrm{ZnMn}_{2} \mathrm{O}_{4}$ nanocrystals were successfully coated with nickel oxide.

Figure 5 shows the $\mathrm{CV}$ curves of $\mathrm{ZnMn}_{2} \mathrm{O}_{4}$ and nickel oxide coated $\mathrm{ZnMn}_{2} \mathrm{O}_{4}$ electrodes at various scan rates ranging from 5 to $100 \mathrm{mV} \cdot \mathrm{s}^{-1}$ in the voltage window of $-0.1-0.7 \mathrm{~V}$. It is obviously that the $\mathrm{CV}$ curves of $\mathrm{ZnMn}_{2} \mathrm{O}_{4}$ samples before and after coating present similar symmetric rectangular shapes without any redox peaks at all scan rates, the $\mathrm{CV}$ curves mean $\mathrm{ZnMn}_{2} \mathrm{O}_{4}$ electrode exhibit a rapid and reversible reaction, easy ion transport and fast spread because of its better electrical double-layer capacitance feature, and showing excellent electrochemical reversibility and ideal capacitive behavior.

Figure 5(c) shows the plots of the specific capacitance values for $\mathrm{ZnMn}_{2} \mathrm{O}_{4}$ and nickel oxide coated $\mathrm{ZnMn}_{2} \mathrm{O}_{4}$ composites in proportion to $\mathrm{CV}$ profile. It is easily found 


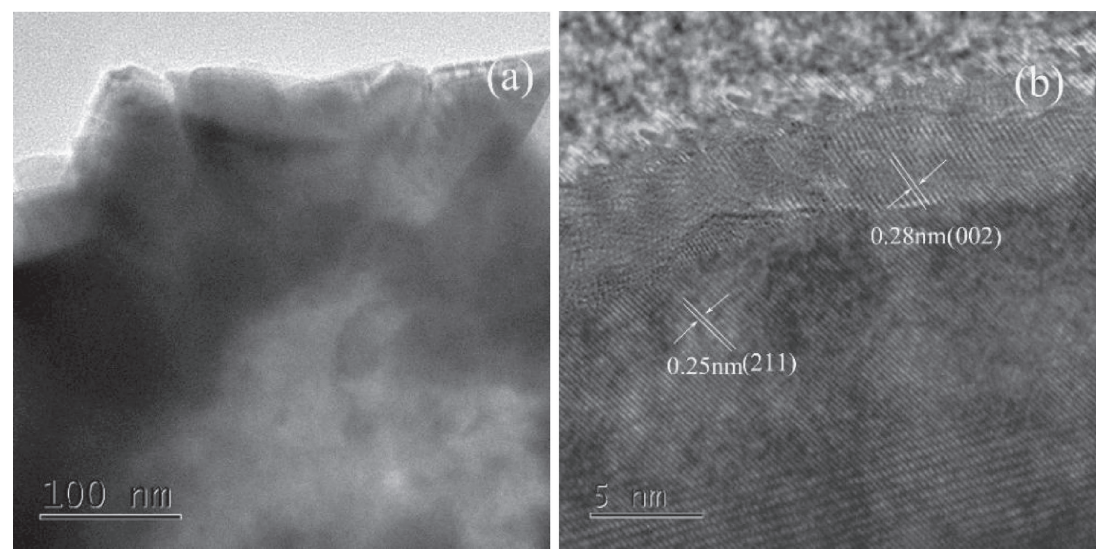

Fig. 4. HRTEM images of nickel oxide coated $\mathrm{ZnMn}_{2} \mathrm{O}_{4}$ composites.
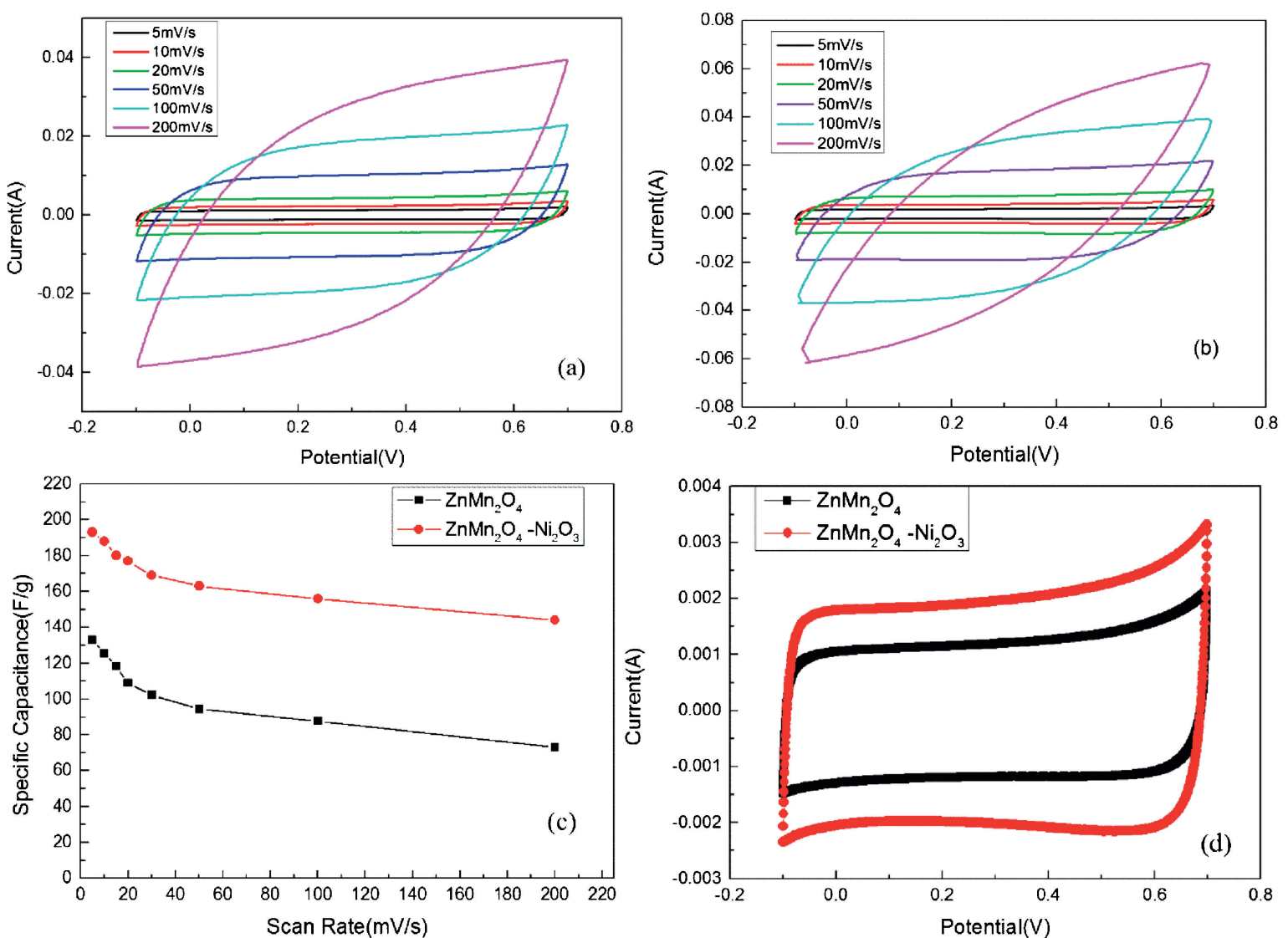

Fig. 5. CV curves of (a) $\mathrm{ZnMn}_{2} \mathrm{O}_{4}$, (b) nickel oxide coated $\mathrm{ZnMn}_{2} \mathrm{O}_{4}$, (c) specific capacitance of samples at different scan rates, (d) $\mathrm{CV}$ curves of $\mathrm{ZnMn}_{2} \mathrm{O}_{4}$ and nickel oxide coated $\mathrm{ZnMn}_{2} \mathrm{O}_{4}$ nanocomposites.

that the specific capacitance of $\mathrm{ZnMn}_{2} \mathrm{O}_{4}$ electrodes decreases gradually with the increase of the scan rate. On the one hand, the energy storage efficiency of the electrode is low due to the insufficient ion transfer between the electrode and the electrolyte interface, on the other hand, the charge transfer reduces the diffusion rate of electrolyte into each electrode materials at higher scan rate. Moreover, the specific capacitance of nickel oxide coated $\mathrm{ZnMn}_{2} \mathrm{O}_{4}$ is obviously better than that of pure $\mathrm{ZnMn}_{2} \mathrm{O}_{4}$ at given scan rate. When the scanning rate is $5 \mathrm{mV} \cdot \mathrm{s}^{-1}$, the estimated maximum specific capacitance for $\mathrm{ZnMn}_{2} \mathrm{O}_{4}$ and nickel oxide coated $\mathrm{ZnMn}_{2} \mathrm{O}_{4}$ samples are 133 and $193 \mathrm{~F} \cdot \mathrm{g}^{-1}$, respectively. Meanwhile, with the scanning rate increasing from 5 to $200 \mathrm{mV} \cdot \mathrm{s}^{-1}$, the capacitance retention rates of $\mathrm{ZnMn}_{2} \mathrm{O}_{4}$ and nickel oxide coating $\mathrm{ZnMn}_{2} \mathrm{O}_{4}$ samples maintain 55 and $75 \%$, respectively. In addition, the specific capacitance of nickel oxide coated $\mathrm{ZnMn}_{2} \mathrm{O}_{4}$ is obviously better than that of $\mathrm{ZnMn}_{2} \mathrm{O}_{4}$ electrodes at a certain scanning rate. Compared with $\mathrm{ZnMn}_{2} \mathrm{O}_{4}$ samples, the superior specific capacitance of nickel oxide coated $\mathrm{ZnMn}_{2} \mathrm{O}_{4}$ composites mainly due to the regular polyhedron architecture with small particle size and large specific surface 

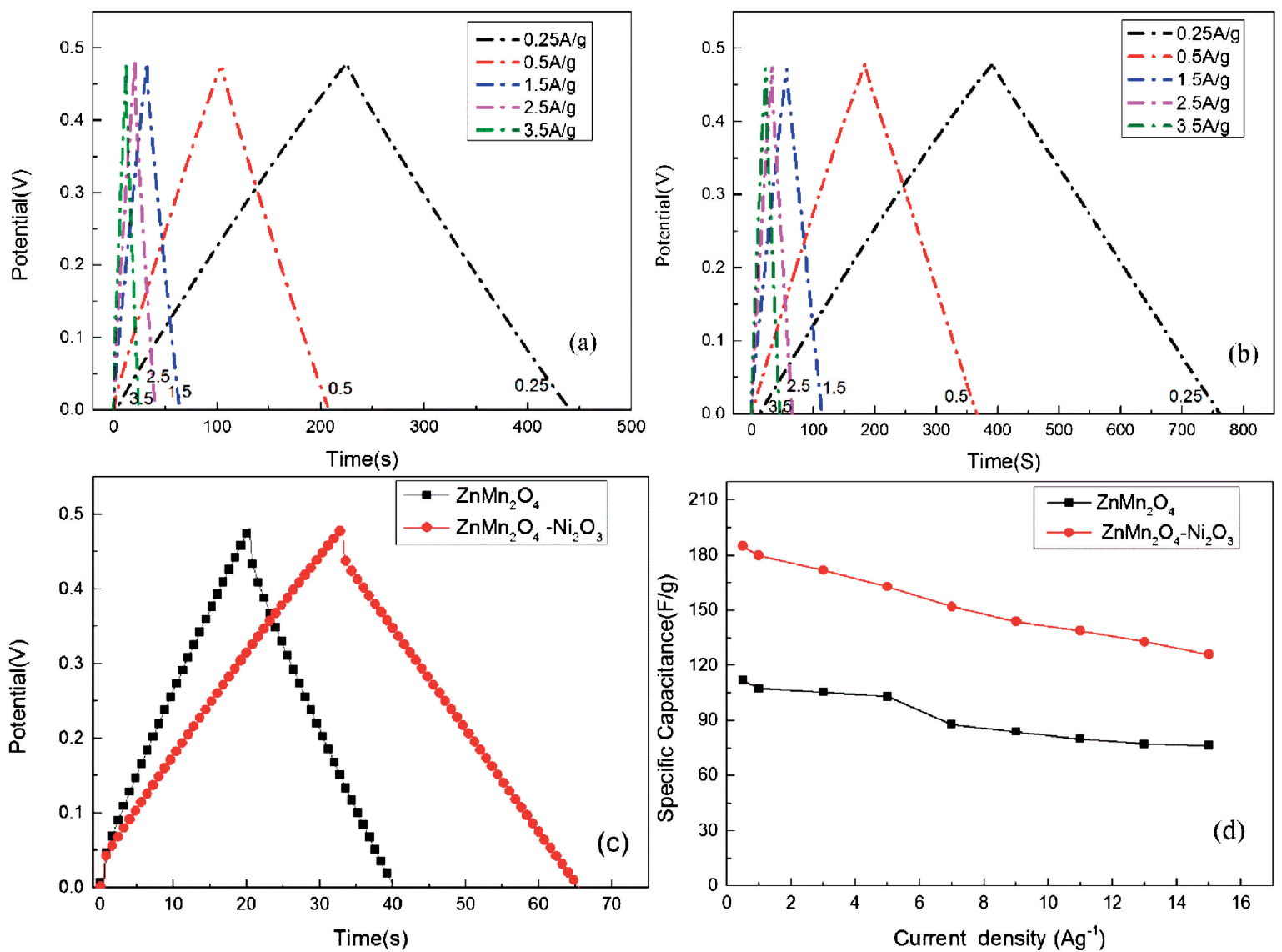

Fig. 6. GCD curves of (a) $\mathrm{ZnMn}_{2} \mathrm{O}_{4}$ and (b) nickel oxide coated $\mathrm{ZnMn}_{2} \mathrm{O}_{4}$ samples at various current densities. (c) GCD curves of $\mathrm{ZnMn}_{2} \mathrm{O}_{4}$ and nickel oxide coated $\mathrm{ZnMn}_{2} \mathrm{O}_{4}$ composites at the current densities of $2.5 \mathrm{~A} \cdot \mathrm{g}^{-1}$, (d) specific capacitance of samples at various current densities.

area, which provides more active sites for Faradaic reactions, improve the movement of ions and electrons, thus promoting the electrochemical properties.

In order to further study the advantages of $\mathrm{ZnMn}_{2} \mathrm{O}_{4}$ and nickel oxide coated $\mathrm{ZnMn}_{2} \mathrm{O}_{4}$ composites, the $\mathrm{CV}$ curves for $\mathrm{ZnMn}_{2} \mathrm{O}_{4}$ and nickel oxide coated $\mathrm{ZnMn}_{2} \mathrm{O}_{4}$ composites were recorded at scan rate $5 \mathrm{mV} \cdot \mathrm{s}^{-1}$ as shown in Fig. 5(d). Obviously, the specific capacitance is proportional to the average area of a $\mathrm{CV}$ curve, and the $\mathrm{CV}$ loop area of nickel oxide coated $\mathrm{ZnMn}_{2} \mathrm{O}_{4}$ composites is much larger than that of $\mathrm{ZnMn}_{2} \mathrm{O}_{4}$, which corresponding to the excellent specific capacitance than pure $\mathrm{ZnMn}_{2} \mathrm{O}_{4}$ samples.

It can be seen that nickel oxide coating can not only change the structure of $\mathrm{ZnMn}_{2} \mathrm{O}_{4}$, but also improve the surface and pore structure of the material. Meanwhile, the existence of nickel oxide coating increases the penetration capacity of cationic ions from the electrolyte to electrode material, and greatly improve the chemical reaction of the electrolyte ions and the surface of the electrode material, which can provide a better electrolyte ion channel, so its energy storage capacity is also better, which can provide a better electrolyte ion channel, and make it have better energy storage capacity.

Figure 6 present the GCD curves for $\mathrm{ZnMn}_{2} \mathrm{O}_{4}$ and nickel oxide coated $\mathrm{ZnMn}_{2} \mathrm{O}_{4}$ samples obtained at various current densities ranging from 0.25 to $3.5 \mathrm{~A} \cdot \mathrm{g}^{-1}$ over the potential window between 0 and $0.48 \mathrm{~V}$ at different current densities. It is clearly that the curves for $\mathrm{ZnMn}_{2} \mathrm{O}_{4}$ samples before and after coating resemble each other quite closely with a nearly linear and isosceles triangle, the charge curves and discharge curves are symmetric at all current densities. The symmetry of the curves indicates that the samples have good invertibility, and the linear nature of the curves suggests that the electrochemical reaction are caused by the super capacitance behavior, which is concordant with the $\mathrm{CV}$ results shown in Fig. 4. The GCD curves for $\mathrm{ZnMn}_{2} \mathrm{O}_{4}$ and nickel oxide coated $\mathrm{ZnMn}_{2} \mathrm{O}_{4}$ samples at current density of $2.5 \mathrm{~A} \cdot \mathrm{g}^{-1}$ are illustrated in Fig. 6(b), it can be seen that charge and discharge time of nickel oxide coated $\mathrm{ZnMn}_{2} \mathrm{O}_{4}$ is longer and the charge and discharge efficiency is higher than that of $\mathrm{ZnMn}_{2} \mathrm{O}_{4}$.

Figure 6(d) shows the specific capacitance of $\mathrm{ZnMn}_{2} \mathrm{O}_{4}$ and nickel oxide coated $\mathrm{ZnMn}_{2} \mathrm{O}_{4}$ at various current densities. The specific capacitance of nickel oxide coated $\mathrm{ZnMn}_{2} \mathrm{O}_{4}$ electrode is obviously higher than that of $\mathrm{ZnMn}_{2} \mathrm{O}_{4}$ at given current density. When the current density $0.25 \mathrm{~A} \cdot \mathrm{g}^{-1}$, the specific capacitance of $\mathrm{ZnMn}_{2} \mathrm{O}_{4}$ and nickel oxide coated $\mathrm{ZnMn}_{2} \mathrm{O}_{4}$ samples are about 186 and $100 \mathrm{~F} \cdot \mathrm{g}^{-1}$, respectively. With the increase of current density, the specific capacitance exhibited a decreasing trend, when the current density increases to $3.5 \mathrm{~A} \cdot \mathrm{g}^{-1}$, the 


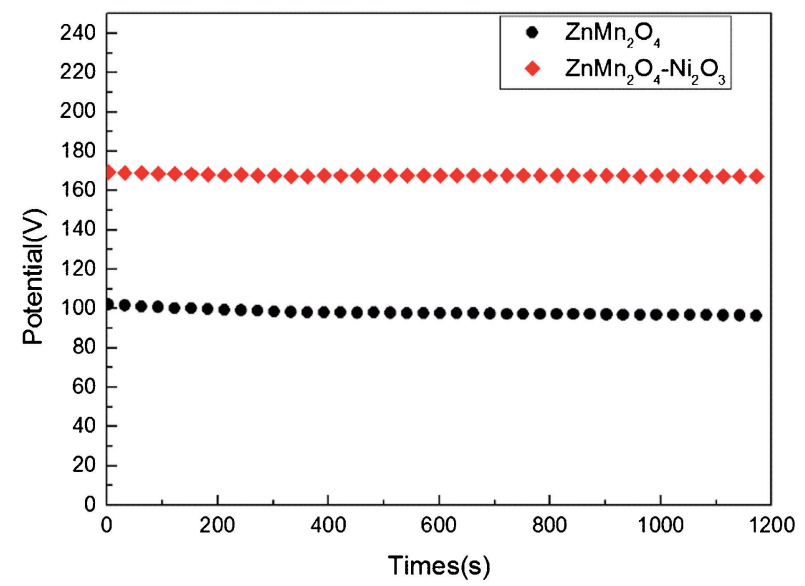

Fig. 7. Cycle stability of $\mathrm{ZnMn}_{2} \mathrm{O}_{4}$ and nickel oxide coated $\mathrm{ZnMn}_{2} \mathrm{O}_{4}$ nanocomposites at current density of $2.5 \mathrm{~A} \cdot \mathrm{g}^{-1}$ over 1200 cycles.

specific capacitance of the samples decreases to 110 and $90 \mathrm{~F} \cdot \mathrm{g}^{-1}$, respectively. In addition, the specific capacitance of nickel oxide coated $\mathrm{ZnMn}_{2} \mathrm{O}_{4}$ electrode at given current density is significantly higher than that of $\mathrm{ZnMn}_{2} \mathrm{O}_{4}$ electrode, nickel oxide coated $\mathrm{ZnMn}_{2} \mathrm{O}_{4}$ electrode exhibit excellent electrochemical performance at high chargedischarge current density. This can be explained by the relatively small size and good dispersion of the regular polyhedron structure, which can provide more available electrochemical reaction of the active site, and lead to the increase of ionic resistivity and reduce charge diffusion of the inner active site and redox reaction rate.

The electrochemical cycling stability for $\mathrm{ZnMn}_{2} \mathrm{O}_{4}$ and nickel oxide coated $\mathrm{ZnMn}_{2} \mathrm{O}_{4}$ as electrode material were evaluated by the repeated charge-discharge measurement at constant current density of $2.5 \mathrm{~A} \cdot \mathrm{g}^{-1}$ for 1200 cycles. Figure 7 exhibits the capacitance retention as a function of the charge-discharge cycling number. The initial specific capacitance for $\mathrm{ZnMn}_{2} \mathrm{O}_{4}$ and nickel oxide coated $\mathrm{ZnMn}_{2} \mathrm{O}_{4}$ samples is 96 and $167 \mathrm{~F} \cdot \mathrm{g}^{-1}$, respectively. After 1200 cycles, the specific capacitances of the samples still remain about 90 and $165 \mathrm{~F} \cdot \mathrm{g}^{-1}$, and maintain about 94 and $99 \%$ of its initial value, respectively. Compared with pure $\mathrm{ZnMn}_{2} \mathrm{O}_{4}$, nickel oxide coated $\mathrm{ZnMn}_{2} \mathrm{O}_{4}$ nanocomposites exhibit better electrochemical performance and stability.

Nickel oxide coated $\mathrm{ZnMn}_{2} \mathrm{O}_{4}$ nanocomposites exhibit excellent electrochemical performance and stability compared with pure $\mathrm{ZnMn}_{2} \mathrm{O}_{4}$ owing to the synergistic effect. On one hand, nickel oxide as active sites coated the surface of $\mathrm{ZnMn}_{2} \mathrm{O}_{4}$ particles and the integration of nickel oxide with $\mathrm{ZnMn}_{2} \mathrm{O}_{4}$ can supply more active sites due to the coexistence of tetrahedral sites and octahedral sites, which can facilitate rapid electrochemical reaction of active material and improve rapid electronic transport from electrode material to the current collector. On the other hand, the regular polyhedron architecture with small particle size and large specific surface area can improve electrochemical behavior and provide more pathways for charge transfer in electrolyte.

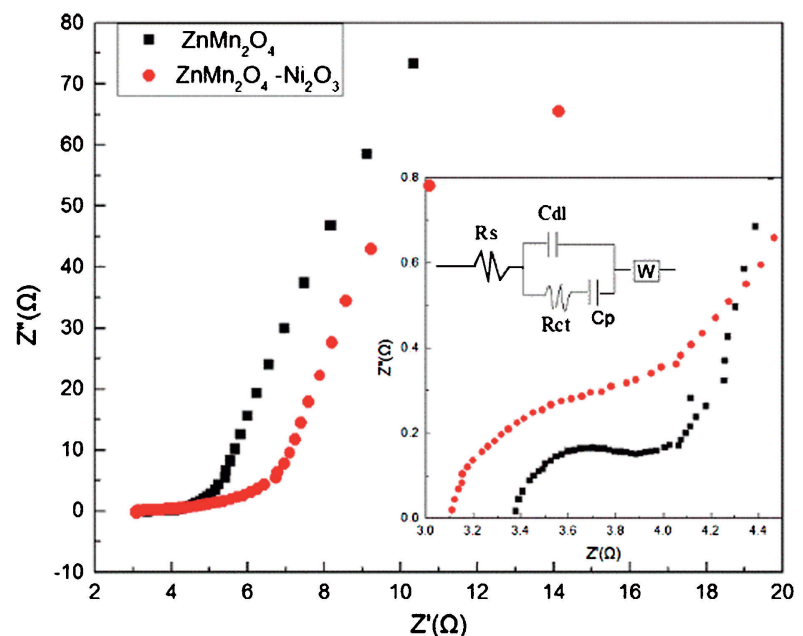

Fig. 8. Nyquist plots of $\mathrm{ZnMn}_{2} \mathrm{O}_{4}$ and nickel oxide coated $\mathrm{ZnMn}_{2} \mathrm{O}_{4}$ nanocomposites.

Figure 8 shows Nyquist plots for $\mathrm{ZnMn}_{2} \mathrm{O}_{4}$ and nickel oxide coated $\mathrm{ZnMn}_{2} \mathrm{O}_{4}$ samples measured in frequency range from $0.01 \mathrm{~Hz}$ to $100 \mathrm{kHz}$, the inset shows the enlarged high frequency region of the spectra and the equivalent circuit. The equivalent circuit including the solution resistance $(R \mathrm{~s})$, charge-transfer resistance $(R \mathrm{ct})$, double layer capacitance $(\mathrm{Cd})$, pseudo capacitance $(\mathrm{Cp})$ and Warburg impedance (W). The Nyquist plots of the impedance spectra contains a semicircle at the high frequency region and a straight line at the low frequency region, where the diameter of the semicircle represents the charge-transfer resistance at the electrode-electrolyte interface, and the slope of the straight line at low frequency represents the Warburg impedance of electrolyte ions diffused into the electrode. The diameters of the semicircle for $\mathrm{ZnMn}_{2} \mathrm{O}_{4}$ and nickel oxide coated $\mathrm{ZnMn}_{2} \mathrm{O}_{4}$ samples are very small (inset of Fig. 7), indicating that the $R \mathrm{ct}$ value is very small, these results indicate that the electrode possess better electrical conductivity, and the Faradic reaction is easy to carry out and has a high reversibility. The phase angle of Nyquist plots for all samples in the mid frequency region higher than $45^{\circ}$ as illustrated from the inset of Fig. 8, which indicates an important capacitive behavior of the sample. In addition, the intersection of Nyquist plots at the $x$-axis represents the internal resistance $(R \mathrm{~s})$, including the ionic resistance of the electrolyte, the intrinsic resistance of electrode materials and the contact resistance at the electrode-electrolyte interface. The Rs values of $\mathrm{ZnMn}_{2} \mathrm{O}_{4}$ and nickel oxide coated $\mathrm{ZnMn}_{2} \mathrm{O}_{4}$ samples is approximately 3.11 and $3.39 \Omega$, respectively. The $R \mathrm{~s}$ value for nickel oxide coated $\mathrm{ZnMn}_{2} \mathrm{O}_{4}$ samples is the lowest, indicating that the sample exhibit rapid electron transfer and the best electrical conductivity, as well as excellent specific capacitance.

\section{Conclusions}

Nickel oxide coated $\mathrm{ZnMn}_{2} \mathrm{O}_{4}$ nanocomposites were successfully synthesized by two-step method combined hydrothermal reaction and calcination process. Nickel 
oxide coated $\mathrm{ZnMn}_{2} \mathrm{O}_{4}$ nanocomposites exhibit weak $\mathrm{Ni}_{2} \mathrm{O}_{3}$ hexagonal phase besides obvious $\mathrm{ZnMn}_{2} \mathrm{O}_{4}$ spinel tetragonal structure, the morphologies are uniform polyhedron shape with obvious cladding layer, and the thickness of cladding layer about $6 \mathrm{~nm}$. The $\mathrm{CV}$ curves are similar to rectangular shape without significant redox peaks. Nickel oxide coated $\mathrm{ZnMn}_{2} \mathrm{O}_{4}$ electrode exhibits better specific capacitance and excellent cyclic stability, and maintains $98.8 \%$ of its initial capacitance after 1200 cycles. Nyquist plots of the samples indicating nickel oxide coated $\mathrm{ZnMn}_{2} \mathrm{O}_{4}$ nanocomposites exhibit lower resistance and ideal electron conductivity.

Acknowledgements This work was supported by the National Natural Science Foundation of China (No.51261015) and the Natural Science Foundation of Gansu Province, China (No. 1308RJZA238).

\section{References}

1) J. Y. Seo, S. N. Lim, S. B. Park and D. S. Jung, J. Ceram. Soc. Jpn., 125, 262-267 (2017).

2) I. Naoya, S. Kazumasa, K. Naoto and I. Yasushi, J. Ceram. Soc. Jpn., 125, 281-286 (2017).

3) X. X. Zhao, H. Yang, S. H. Li, Z. M. Cui and C. R. Zhang, Mater. Res. Bull., 107, 180-188 (2018).

4) Y. Omori, T. Honma and T. Komatsu, J. Ceram. Soc. Jpn., 126, 820-825 (2018).

5) W. H. Zhao, Z. Q. Wei, X. L. Zhu, X. D. Zhang and J. L. Jiang, Int. J. Mater. Res., 109, 405-412 (2018).

6) T. Zhang, L. B. Kong, M. C. Liu, Y. H. Dai, K. Yan, B. $\mathrm{Hu}$, Y. C. Luo and L. Kang, Mater. Design, 112, 88-96 (2016).

7) W. J. Ma, S. H. Chen, S. Y. Yang, W. P. Chen, Y. H. Cheng, Y. W. Guo, S. J. Peng, R. Seeram and M. F. Zhu, J. Power Sources, 306, 481-488 (2016).

8) F. Y. Ke, Y. Liu, H. Y. Xu, Y. Ma, S. Y. Guang, F. Y. Zhang, N. B. Lin, M. D. Ye, Y. H. Lin and X. Y. Liu, Compos. Sci. Technol., 142, 286-293 (2017).

9) G. R. Xu, X. P. Min, Q. L. Chen, Y. Wen, A. P. Tang and H. S. Song, J. Alloy. Compd., 691, 1018-1023 (2017).

10) M. Huang, Y. X. Zhang, F. Li, L. L. Zhang, Z. Y. Wen and Q. Liu, J. Power Sources, 252, 98-106 (2014).

11) J. J. Zou, B. Liu, H. Q. Liu, Y. H. Ding, T. Xin and Y. Q. Wang, Mater. Res. Bull., 107, 468-476 (2018).
12) Y. Luo, T. Y. Yang, Q. Zhao and M. Z. Zhang, J. Alloy. Compd., 729, 64-70 (2017).

13) X. M. Wu, Q. G. Wang, W. Z. Zhang, Y. Wang and W. X. Chen, Electrochim. Acta, 211, 1066-1075 (2016).

14) P. E. Saranya and S. Selladurai, J. Mater. Sci.-Mater. El., 29, 3326-3339 (2018).

15) Y. Ito, M. Konishi, K. Noi, M. Deguchi, A. Hayashi and M. Tatsumisago, J. Ceram. Soc. Jpn., 126, 475-481 (2018).

16) X. L. Zhu, Z. Q. Wei, W. H. Zhao, X. D. Zhang and J. L. Jiang, Curr. Nanosci., 14, 474-480 (2018).

17) J. L. Jiang, X. X. He, J. F. Du, X. J. Pang, H. Yang and Z. Q. Wei, Mater. Lett., 220, 178-181 (2018).

18) F. Wang, H. Yang, H. M. Zhang, J. Y. Su and X. X. Wang, J. Electron. Mater., 46, 182-187 (2017).

19) W. H. Zhao, Z. Q. Wei, X. J. Wu, X. D. Zhang, L. Zhang and X. Wang, Mat. Sci. Semicon. Proc., 88, 173180 (2018).

20) Y. F. Dong, Z. S. Wu, W. C. Ren, H. M. Cheng and X. H. Bao, Sci. Bull., 62, 724-740 (2017).

21) R. Gherbi, Y. Bessekhouad and M. Trari, J. Alloy. Compd., 655, 188-197 (2016).

22) X. L. Zhu, Z. Q. Wei, W. H. Zhao, X. D. Zhang and J. L. Jiang, J. Electron. Mater., 47, 6428-6436 (2018).

23) J. Bhagwan, N. Kumar, K. L. Yadav and Y. Sharma, Solid State Ionics, 321, 75-82 (2018).

24) W. C. Wang, Y. L. Yuan, J. Yang, L. Meng, H. C. Tang, Y. J. Zeng, Z. Z. Ye and J. G. Lu, J. Mater. Sci., 53, 6116-6123 (2018)

25) W. J. Ma, S. H. Chen, S. Y. Yang, W. P. Chen, Y. H. Cheng, Y. W. Guo and S. J. Peng, J. Power Sources, 306, 481-488 (2016).

26) X. M. Cai, X. G. Cui, L. Zu, Y. Zhang, X. Gao, H. Q. Lian, Y. Liu and X. D. Wang, Polymers, 19, 288 (2017).

27) B. Ameri, S. S. H. Davarani, H. R. Moazami and H. Darjazi, J. Alloy. Compd., 720, 408-416 (2017).

28) Q. Liu, Z. Zhang, B. Liu and H. Xia, Appl. Catal. BEnviron., 237, 855-865 (2018).

29) M. Abdollahifar, S. S. Huang, Y. H. Lin, Y. C. Lin, B. Y. Shih, H. S. Sheu, Y. F. Liao and N. L. Wu, J. Power Sources, 378, 90-97 (2018).

30) F. M. Courtel, Y. Abu-Lebdeh and I. J. Davidson, Electrochim. Acta, 71, 123-127 (2012).

31) T. Zhang, Y. Gao, H. Yue, H. Qiu, Z. Guo, Y. Wei, C. Wang, G. Chen and D. Zhang, Electrochim. Acta, 198, 84-90 (2016). 